\title{
Purchasing in a Pandemic? Virtual Consumerism in 2021
}

\author{
Brenda K. Wiederhold, PhD, MBA, BCB, BCN
}

$\mathbf{U}$ SHERED IN BY AMAZON and fueled by the coronavirus disease 2019 (COVID-19) pandemic, virtual consumerism (VC) is more than simply the act of buying products on the Internet. The term encompasses entire economies and the study of each facet of these intricate new systems. Modern technologies, buoyed by current world conditions and trends, have enabled the creation of a seemingly inexhaustible parade of consumer products and services, forming new markets and effectively blurring the boundary between "virtual" and "real" consumerism. VC is an evolving and essential topic, encompassing virtual reality (VR)/mixed reality (MR)/extended reality/augmented reality (AR), avatars and embodiment, online shopping, consumerism in online games, virtual consumer health, and supportive technologies, and cutting across many different segments of online and consumer behaviors.

For years, studies on information technology consumption focused on the use of the technologies and devices themselves, examining questions such as who uses the Internet and how many people have access to mobile devices. ${ }^{1}$ Now, VC research has expanded. The infiltration of digital technology into all aspects of life has had a profound impact on the way people consume all types of goods and services, not just those related to advanced technologies. Every product one considers purchasing is examined with high scrutiny, inspected, compared, and often purchased on the Internet using mobile devices and services. Product information is then dispersed and discussed on sites, blogs, and forums Internet wide.

Though the VC industry was growing exponentially prior to 2020, the COVID-19 crisis spurred its evolution in a way most never predicted. Consumer attitudes, behaviors, and habits have changed due to the restrictions imposed by the pandemic, and researchers are beginning to explore which of these will remain post pandemic. While many purchases made at this time are aimed toward satisfying consumers' basic needs, trends indicate ${ }^{2}$ that consumers are also moving toward shopping more consciously and locally, and are embracing digital ways of connecting with others during this time of isolation. Of the trends that make up the field of VC, five main areas are seeing immense growth and change during the pandemic: the online retail space, customer service and interaction, marketing, virtual entertainment, and virtual health.

Online shopping is what most people think of when they hear the term VC, and it is a large part of what runs the digital economy. Online shopping is lauded for being more convenient than in-person shopping, allowing consumers to take their time, comparison shop, and choose from seemingly unlimited options, all from the comfort of their own homes.
One of the most-cited downsides to online shopping is the lack of a real-world experience and the ability to touch and feel a product in order to verify its quality before purchase. This is where advanced technologies such as artificial intelligence and AR/MR/VR tools come in. These technologies allow for apps such as those that enable consumers to "tryon" different clothes, glasses, make-up, and even hairstyles. Real-world VC applications for brick-and-mortar locations may include increased efficiency for returns and exchanges, reduced human interaction (a benefit during the pandemic), customer behavior predictions, and logistics management. ${ }^{3}$ Augmented tools improve the purchasing process for contemporary shoppers, rendering it more "experiential" both in-person and online. ${ }^{4}$

Another retail area gaining popularity is the sale of virtual items for real currency. 5 Often used as a revenue model in games, this practice is gaining popularity in other online services as well. Research into how some media representations come to be perceived as "virtual commodities" has grown, as has the study of what may motivate individuals to spend money in this way and how the resulting "virtual consumerism" relates to consumer culture at large.

Advanced technology is also allowing customers and companies to begin to interact in new and innovative ways. From early beta testing of products to personalized customer service queries and responses from consumer assistants, the formal relationship between consumers and the companies they patronize has changed. Technologically savvy customers are able to construct customized news feeds, monitor their financial accounts, explore real-estate properties, and take care of many of their interactions with businesses all at a distance on their mobile devices. ${ }^{6}$ As they are now often allowed into their customers' personal spaces, companies have a unique opportunity to drive stronger relationships with their consumers.

For marketing purposes, companies and researchers are constantly monitoring how consumers think, behave, and buy. Advanced technologies such as VR and AR are having a significant impact on many traditional marketing practices, and are attracting increasing attention from marketing researchers. ${ }^{7}$ In order to deliver the virtual quality that online customers expect, e-marketers and Web site designers are working to understand not only the markets they operate in, but also what influences online consumers: their needs, motives, and buying behaviors. Research also includes examinations of the nature, power, and function of available online marketing tools and their efficient use to influence customers' decision-making processes and choices positively. ${ }^{8}$ 
In addition to online shopping, during this time when many are isolated from loved ones and are not able to use traditional coping mechanisms, the use of technology for entertainment purposes has skyrocketed. Virtual experiences have brought retail, museums, travel destinations, and education into consumers' homes. The year 2020 also saw a rise in subscription culture. For example, Netflix announced 16 million new subscribers globally in April 2020 - the month following lockdown orders in many countries-with 7.5 million more forecasted for the months leading to June. ${ }^{9}$ Being able to access high-quality content immediately has become a generation-defining capability. ${ }^{3}$

Finally, the virtual health care field, already immense in its reach and capabilities, continues to grow. Technology has given patients more access to and control over their healthcare needs, allowing people to feel more confident that they are taking the best care possible of themselves and their loved ones. Especially where non-acute care is concerned, telehealth has a huge role to play. As the traditional system is overloaded with a snowballing volume of need, and consumers increasingly look for convenient solutions to their health care needs, virtual care can fill the gap. Especially due to pandemic concerns, regulatory conditions, economic imperatives, and consumer expectations have all aligned in favor of online health care. ${ }^{10}$

Though this discussion is far from exhaustive, it is representative of the depth and breadth of this growing field. Because VC is so rich and nuanced, and it is expanding and changing so rapidly at this time in history, it is an area ripe for investigation and research.

\section{References}

1. Lehdonvirta V. (2012) A history of the digitalization of consumer culture: from Amazon through Pirate Bay to
FarmVille. In Denegri-Knott J, Molesworth M, eds. Digital virtual consumption. New York: Routledge, pp. 11-28.

2. COVID-19: how consumer behavior will be changed. https://www.accenture.com/us-en/insights/consumer-goodsservices/coronavirus-consumer-behavior-research (accessed Dec. 21, 2020).

3. Roberts B. Top 5 trends that could change 2021 consumerism. https://www.licenseglobal.com/retail-trends/ top-5-trends-could-change-2021-consumerism (accessed Dec. 21, 2020)

4. Virtual consumerism. https://www.trendhunter.com/ protrends/virtual-consumerism (accessed Dec. 21, 2020).

5. Lehdonvirta V, Wilska T-A, Johnson M. Virtual consumerism. Information, Communication \& Society 2009; 12: 1059-1079.

6. Venkatraman N, Henderson JC. Real strategies for virtual organizing. https://sloanreview.mit.edu/article/real-strategiesfor-virtual-organizing/ (accessed Dec. 21, 2020).

7. Wedel M, Bigné E, Zhang J. Virtual and augmented reality: advancing research in consumer marketing. International Journal of Research in Marketing 2020; 37.

8. Constantinides E, Geurts P. The impact of web experience on virtual buying behaviour: an empirical study. Journal of Customer Behaviour 2005; 4.

9. Jarvey N. Netflix adds nearly 16 million subscribers amid virus shutdown. https://www.hollywoodreporter.com/news/ netflix-adds-16-million-subscribers-virus-shutdown-1291168 (accessed Dec. 21, 2020).

10. Verstraete $S$. A new year and new opportunities for virtual care. https://teladochealth.com/blog/a-new-year-and-newopportunities-for-virtual-care/ (accessed Dec. 21, 2020).

Brenda K. Wiederhold Editor-in-Chief 